\title{
Picasso 'visita' o Recife: a exposição da Escola de Paris em março de 1930
}

\author{
MOACIR dOS ANJOS JR. e JORGE VENTURA MORAIS
}

$\mathrm{Q}$

UE PABLO PICASSO nunca veio ao Recife, quase todos sabem. O que poucos parecem saber é que, já em março de 1930, uma obra sua foi exposta no salão nobre do Teatro Santa Isabel, local de alguns dos mais importantes acontecimentos culturais e políticos da cidade (1). Mais ainda, desconhecem que ela não estava sozinha, mas na companhia de cerca de 90 outros trabalhos de artistas da chamada Escola de Paris, como Braque, Dufy, Gris, Léger, Miró, Severini, Vlaminck e Rego Monteiro. Mas o que talvez um número ainda menor de pessoas saiba é que foi deste último - o pernambucano, então residente em Paris, Vicente do Rego Monteiro - a idéia de trazer a exposição ao Brasil. E é dessa rara e quase esquecida 'visita' - um evento de modo algum desimportante - que se trata neste texto.

A relevância da exposição da Escola de Paris está, em primeiro lugar, no fato de alguns dos artistas ali representados terem sido os responsáveis por várias das grandes inovações nas artes plásticas nas primeiras décadas do século XX, tais como o fovismo, o cubismo e o surrealismo. Mas foi igualmente marcante por ter sido a primeira grande exposição de arte moderna européia a desembarcar no Brasil e a única, de porte equivalente, de que se teria notícia nos dez anos seguintes (2). A importância do evento foi logo reconhecida pelo mundo artístico brasileiro, como é testemunho o depoimento dado por Tarsila do Amaral em janeiro de 1931: para a pintora paulista, a mostra havia sido, juntamente com a abertura da Casa Modernista de Gregori Warchavchik, “o fato mais importante do ano de 1930" em São Paulo, terceira e última cidade - após o Recife e o Rio de Janeiro - do roteiro seguido pela exposição (Zanini, 1983:816).

A despeito de seu inequívoco pioneirismo e de sua indisputada relevância, a mostra parece ter sido um fracasso de público onde quer que tenha passado. Segundo depoimento do próprio Vicente do Rego Monteiro, a “incompreensão... foi grande e o lucro nenhum” (Bento, 1994:62). E por não ter repercutido como era esperado, há hoje poucos registros sobre a passagem da Escola de Paris pelo Brasil em 1930, e ainda mais escassas, se 
não inexistentes, são as tentativas de entender as razões da apatia, ou mesmo desdém, com que foi recebida. Tamanho e tão rápido foi o esquecimento da exposição que, mesmo no número especial editado pela revista pernambucana Contraponto (1950) para comemorar o centenário do Teatro Santa Isabel, não há referência ao evento. Além de esparsas notícias da época, existem apenas, sobre o fato, curtas menções e compactas notas de pé-depágina em compêndios de história da arte no Brasil ou em textos biográficos sobre a trajetória do pintor pernambucano (3).

Diante de tal quadro, o objetivo dos autores neste artigo é duplo: por um lado, resgatar, factualmente, o ineditismo da exposição da Escola de Paris no Recife, agrupando e compatibilizando informações dispersas e fragmentadas em várias fontes; por outro, propor uma explicação para o fato de a mostra não ter sido bem recebida pelo público que a visitou no Teatro Santa Isabel. Apesar da descrença do crítico Antonio Bento (1994), para quem o fracasso da exposição seria, diante de sua inequívoca qualidade, "inexplicável”, sugere-se, a seguir, uma interpretação sociológica das razões por que Pablo Picasso passou despercebido nos trópicos. Antes, porém, para que não se adicionem ainda mais imprecisões ao tema, é preciso lembrar, mesmo que de modo breve, o que era o mundo no Recife de tantas décadas atrás.

\section{Os anos 20 no Recife}

A exposição da Escola de Paris acontece ao final de um período de grande efervescência cultural no Recife. Ao longo dos anos que a antecedem, a cidade testemunha mudanças em ritmo e de natureza até então não experimentados por seus habitantes. Guardadas as proporções, o frenesi da era do jazz, observado nas grandes metrópoles mundiais, também aporta no Recife. A cidade maurícia, espantada, se fazia moderna (4).

Recife é também palco, nos anos 20, de fascinante embate entre distintas propostas de construção de uma identidade nacional. De um lado, estavam os regionalistas, que, liderados por Gilberto Freyre, buscavam estabelecer, através do resgate e da preservação das raízes e tradições nordestinas, a especificidade da cultura brasileira. Momento exemplar de tal processo é o Livro do Nordeste, organizado por Freyre em 1925. Além de mapear e demarcar, em diversas áreas temáticas, as manifestações e vestígios daquela herança cultural, o Livro buscava, talvez até como objetivo principal, afirmar a Região Nordeste como berço da nacionalidade brasileira (Freyre et al., 1925). Em desacordo com tal projeto, outro grupo de intelectuais e artistas, à frente o jornalista Joaquim Inojosa, empenhou-se em semear, no Recife e 
em todo o Nordeste, o ideário do movimento modernista deflagrado em São Paulo (5). Nessa disputa entre regionalismo e modernismo, o último era freqüentemente acusado por Freyre de propor a europeização da cultura brasileira, enquanto o primeiro se buscava fazer notar como refúgio da 'alma' e das 'reminiscências' do país, ameaçadas que estariam por um conceito 'apressado' de modernização. Inojosa, por sua vez, atribuía aos regionalistas um sentimento 'passadista', nostálgico de um passado patriarcal, reivindicando para seu grupo a missão de tornar a arte nordestina contemporânea do espírito moderno (Dimas, 1996).

Apesar da ferocidade com que regionalistas e modernistas usualmente defendiam suas propostas, o embate entre os dois grupos arrefeceu ao final da década. Uma das razões da calmaria foi a guinada do movimento modernista rumo à trilha das raízes culturais brasileiras, o que diminuiu o fosso que separava as duas visões (Azevedo, 1996). Outra, de ainda maior importância, parece ter sido a insistência dos modernistas pernambucanos em reproduzir, sem as necessárias mediações e espírito crítico, fórmulas de compreensão e discussão do mundo que pouca ressonância encontravam em um Recife ávido por afirmar a relevância de sua herança cultural.

A perda de fôlego da campanha modernista pernambucana não significou, entretanto, o desaparecimento das idéias e conceitos estéticos associadas ao modernismo. O que some são os antagonismos vitais, as lutas cegas, a má-vontade com o olhar do outro. Em tal ambiente, as vozes que passam a se destacar são aquelas que conseguem articular, numa dicção eivada de sotaque moderno, os valores e tradições que inserem Pernambuco e o Nordeste no repertório de mundos possíveis. Dentre estas, ganha unânime destaque a do poeta Ascenso Ferreira. Inclassificável, Ascenso talvez tenha sido a melhor tradução da definição que, buscando explicar a si próprio, Gilberto Freyre havia formulado anos atrás: regionalista, tradicionalista e, a seu modo, modernista.

É importante destacar que quase toda a discussão entre regionalistas e modernistas ficou restrita ao mundo das letras recifense, por meio de artigos, ensaios, manifestos e poemas, todos veiculados pelo razoavelmente bem instalado parque gráfico e editorial da cidade. Pouco do dinamismo aí observado transbordou para o campo das artes plásticas, o qual não conseguiu estabelecer, em termos próprios, os elementos do confronto travado no campo literário local. E uma das principais razões para a debilidade desse debate estético era a quase inexistência de instituições (museus, galerias, crítica, escolas de arte, salões, etc.) por intermédio das quais discussões conceituais pudessem ser conduzidas e inovações introduzidas no mundo das artes plásticas (Cf. Bourdieu, 1993a; Becker, 1974). 
Reconhecer o acanhamento das instituições do campo artístico pernambucano não basta, contudo, para compreender sua pouca permeabilidade à arte moderna. É preciso também explicitar algumas das principais características das artes plásticas locais no início do século, dentre as quais se destaca a grande influência exercida pelo pintor acadêmico Jerônimo José Teles Júnior. Descrevendo a paisagem da Zona da Mata pernambucana em inúmeras telas, Teles Júnior, falecido em 1914, deixou como legado a idéia de que a pintura deveria preservar o sentimento de pertencimento do artista ao local onde vive. Esta visão telúrica da arte foi absorvida não somente por pintores pernambucanos, como Walfrido Mauricéia, mas também por estrangeiros residentes no estado, como o francês Eugênio Lassailly, que fixou em cores e formas a vida nos engenhos de açúcar de Pernambuco.

Escrevendo sobre pintura no Livro do Nordeste, Gilberto Freyre (1925) destaca a importância de Teles Júnior para o desenvolvimento de uma pintura regionalmente situada, plantada no que é próprio ao espaço em que vive o artista; aponta também, entretanto, o que seria a grande insuficiência de sua obra e da de seus seguidores: a falta do elemento interpretativo, o contentar-se com a mera documentação, a quase inexistência dos tipos humanos locais como animadores de suas paisagens. É só às vésperas da década de 1920, mediante os vaqueiros, feirantes e agricultores pintados pelo filho de ingleses Henrique Elliot, que a pre-sença de motivos regionais reclamada por Freyre começa a se insinuar na arte pernambucana (Cláudio, 1982). Nem nesse momento, contudo, o academicismo da obra de Teles Júnior é questionado, contaminando a descrição pictórica dos tipos da região.

Ao longo dos anos 20 são muitos os pintores que, em um contexto de afirmação de identidade cultural, buscam definir, em suas obras, a especificidade da arte pernambucana: uns, pela atualização da tradição paisagista consolidada por Teles Júnior (Álvaro Amorim, Mário Nunes, Mário Túlio); outros, pela investigação minuciosa das cenas e dos tipos característicos de uma ainda incerta 'pernambucanidade' (Eliezer Xavier, Carlos Chambelland, Lula Cardoso Ayres). Mas, a despeito de serem ou não paisagistas, o certo é que eles adotam o lugar de origem como guia quase único de seu itinerário estético, exacerbando o entranhamento da pintura feita no estado com as coisas da terra $(6)$.

Tal ensimesmamento está na raiz não apenas da singularidade da arte feita em Pernambuco, mas também no enfraquecimento de sua já pequena capacidade de absorver e recriar inventos artísticos surgidos no âmbito de outras tradições. Ocupados em dar forma aos temas e tipos que os localizavam e distinguiam no mundo, os artistas locais descuidaram-se da tarefa - crucial para a arte moderna - de refazer, criticamente, as convenções 
acadêmicas de que se utilizavam. Assim, apesar de a estética modernista ter sido gradualmente incorporada à literatura e ao ensaísmo feitos em Pernambuco nos anos 20 (sem, contudo, implicar o abandono das referências regionais), pouco dela foi absorvido pelo mundo das artes plásticas. De fato, não foram muitos os artistas plásticos pernambucanos que buscaram investigar a mitologia regional a partir de um diálogo com o modernismo. Dentre estes poucos, contudo, dois se destacam por sua intensa originalidade: Cícero Dias e Vicente do Rego Monteiro. Não por acaso, ambos passaram quase toda a década afastados do Recife (7).

Vivendo no Rio de Janeiro desde a adolescência, Cícero Dias reconstruiu, em uma linguagem onírica que o aproximava dos surrealistas, a paisagem e os tipos dos canaviais de Pernambuco. Em óleo ou aquarela, sobre tela ou papel, o menino do engenho Jundiá despiu-se tão completamente de atavismos castradores que pôde anunciar, em formas absolutamente estranhas à imagística dos pintores pernambucanos e com a autoridade que o artista se lhe confere, a artificialidade da propalada oposição entre regionalismo e modernismo. Em painel de $15 \mathrm{~m}$ x $3 \mathrm{~m}$, atônito com sua descoberta, Cícero bradou: "Eu vi o mundo, ele começava no Re cife". Apesar de eloqüente, seu grito chegou tarde, ao fim de uma década em que os recifenses pouco puderam refletir sobre o universo visual da arte moderna e em que desconfianças estéticas já se cristalizavam. Além disso, a presença de Cícero Dias em seu estado natal foi por demais avara para que sua voz adquirisse a legitimidade possuída pelo filho da terra e fosse, ao menos, escutada com atenção (8).

Um pouco diferente foi a sorte de Vicente do Rego Monteiro. Tendo vivido em Paris entre 1911 e 1915, volta ao Brasil após a deflagração da Primeira Guerra Mundial, aos 15 anos de idade e já com a experiência de ter freqüentado várias escolas de pintura (entre elas a Academia Julian e a Academia Colarossi) e de ter participado, em 1913, do Salon des Indépendants (Monteiro, 1969). Entre 1919 e 1921, Monteiro faz várias exposições individuais no Recife, no Rio de Janeiro e em São Paulo, sendo, a partir de então, gradualmente reconhecido por seus conterrâneos como um dos poucos artistas de Pernambuco (e do Brasil) capazes de elaborar uma fusão entre o apego a tipos e motivos nacionais e a necessidade de dialogar com as experimentações artísticas em curso no mundo.

Dando forma plástica às influências da estada européia, ele refunda, em uma original recriação dos volumes e luzes cubistas, mitos amazônicos e tipos brasileiros, antecipando princípios estéticos que seriam caros tanto aos regionalistas quanto aos modernistas brasileiros: Vicente não apenas fixa o que é regional, mas o interpreta de uma forma nova, destituída de ví- 
cios e acomodações academicistas. Não espanta, portanto, que o regionalista Gilberto Freyre (1925) e o modernista Ronald de Carvalho (1921) tenham concordado nos elogios concedidos ao pintor pernambucano. Aliás, é pelas mãos de Ronald de Carvalho que várias de suas telas são incluídas na Semana de Arte Moderna de 1922, ao lado dos trabalhos de Brecheret, Di Cavalcanti e Anita Malfatti. Antes disso, porém, ainda em 1921, retorna a Paris, onde amadureceria sua obra e permaneceria até o início de 1930.

Pela natureza sincrética de seu trabalho, é possível imaginar que Vicente do Rego Monteiro poderia ter desempenhado, no campo das artes plásticas pernambucano dos anos 20, o papel que Ascenso Ferreira desempenhou no campo literário: o de estabelecer pontos de passagem e convergência entre os discursos regionalista e modernista.

O acanhamento do campo artístico recifense, contudo, somado à longa ausência do pintor, não permitiu que suas invenções pictóricas tivessem, em Pernambuco, a ressonância que a poesia de Ascenso ali alcançou ao final da década. Não deixa de ser emblemático daquela natureza, porém, que tenha sido pelas mãos de Vicente que, pela primeira vez, uma exposição com os mais representativos artistas modernistas europeus tenha chegado a Pernambuco e ao Brasil.

\section{Picasso 'desembarca' no Recife}

Vivendo em Paris durante quase toda a década de 1920, Vicente do Rego Monteiro pôde continuar seu projeto de recriação de mitos e tipos brasileiros a partir das inovações artísticas com que se defrontava na capital francesa. Neste processo, não apenas estabeleceu contato com a vanguarda artística parisiense, mas passou também a ser reconhecido, por artistas, público e marchands, como um dos membros da Escola de Paris (Cf. Ayala, 1994).

Dentre as relações pessoais então travadas, seria particularmente importante para sua carreira a amizade feita com o crítico e poeta francês Géo-Charles, com quem trabalhou na revista Montparnasse. E foi em sua companhia que, em 1930, Vicente finalmente voltou ao Brasil, em circunstâncias que ele próprio esclarece:

Vim a convite do meu cunhado, [que] queria que eu fosse padrinho da filhinha dele. Ela já fazia mais de 3 anos e en me achei na obrigação de vir ao Brasil para o batizado. Para ter um motivo justificado, eu realizei esta exposição, com um companheiro chamado Géo-Charles [...] Então eu resolvi fazer uma coleta prévia de quadros, entre os marchands 
mais importantes de Paris, como Rosenberg e outros, amigos meus. Eles me cederam quadros de autores diversos, como Braque, Marcoussis, Léger, Picasso, Dufy, Papazof, enfim, outros nomes menos conhecidos. A minha idéia era a seguinte: mostrar no Brasil minha pintura ao lado da pintura de meus companheiros da Escola de Paris, da qual fazia parte. Esse foi meu intuito (Monteiro, 1969:256).

Essa foi a primeira exposição internacional de arte moderna trazida ao Brasil. Apesar de seu ineditismo, vale ressaltar que a mesma não contou com qualquer ajuda oficial para o financiamento de transporte ou seguro das obras, tudo sendo arranjado em função dos contatos pessoais de Monteiro com o mundo das artes parisiense.

A revista Montparnasse, à época administrada por Vicente e dirigida por Géo-Charles, aparece como organizadora do evento, tendo mesmo publicado um número especial dedicado à mostra da Escola de Paris no Brasil (Zanini, 1997).

Já em Recife, a exposição contou com o apoio oficial do Governo do Estado de Pernambuco, tendo sido montada no salão nobre do Teatro Santa Isabel, no período de 21 de março a 2 de abril de 1930 (A Província, 19/3 e $3 / 4 / 1930)(9)$.

Registre-se, entretanto, que até mesmo esse pequeno apoio só foi conseguido por meio de uma relação pessoal de Vicente do Rego Monteiro.

Foi Aníbal Fernandes, casado com sua irmã Fédora e então conservador do Museu do Estado de Pernambuco, quem obteve a permissão do governador Estácio Coimbra para utilizar o teatro como local do evento (Bento, 1994; Zanini, 1997).

Ao contrário do que atualmente ocorre, quando os vernissages acontecem à noite e contam, quase tão-somente, com a presença de admiradores do(s) $\operatorname{artista(s)~e/ou~de~entusiastas~de~artes~plásticas,~a~abertura~da~exposição~}$ deu-se às 15 horas de uma sexta-feira e reuniu tout le monde de um Recife ainda pouco acostumado a tais rebuliços.

Com efeito, além das "tradicionais famílias da sociedade pernambucana", artistas, jornalistas, músicos e literatos, todas as principais autoridades estaduais - o próprio governador, o prefeito da capital, o chefe da polícia, o general comandante da região, o comandante da força pública, secretários de estado, deputados e senadores - compareceram ao evento ( $A$ Provincia, 20/3 e 22/3/1930). 
Artistas e obras na exposição da Escola de Paris em Recife (1930)

\begin{tabular}{|c|c|c|c|}
\hline Artistas & Obras & Artistas & Obras \\
\hline André Bauchant & "Eve au Paradis" & Marie Laurencin & $?$ \\
\hline Marie Blanchard & "Tete de Femme" & Henri Laurens & "Composition" \\
\hline Borrès & "Jeux de Cartes" & Henri Le Fauconnier & "Sous Bois" \\
\hline Bouquet & $?$ & Fernand Léger & $\begin{array}{l}\text { "Composition" (óleo); } \\
\text { "Paysage" (aquarela); } \\
\text { "Composition" (des.) }\end{array}$ \\
\hline Bosshard & "Nymphe" & André Lhote & $\begin{array}{l}\text { "Femme au Chapeu" } \\
\text { (óleo); "Football" } \\
\text { (aquarela). }\end{array}$ \\
\hline Georges Braque & $\begin{array}{l}\text { "Compositions" } \\
\text { (quatro litogravuras) }\end{array}$ & Maurice Loutreuil & $\begin{array}{l}\text { "L'Homme Assis"; } \\
\text { "Tete de Femme }\end{array}$ \\
\hline Massimo Campigli & "Buste de Femme" & Jean Lurçat & “Nu Dans le Paysage" \\
\hline Clément & $\begin{array}{l}\text { "Le Port"; } \\
\text { "Le Joupon Jaune"; } \\
\text { "Saltibanques" }\end{array}$ & Louis Marcoussis & $\begin{array}{l}\text { "Compositions" (dois } \\
\text { óleos); "Composition" } \\
\text { (água-forte) }\end{array}$ \\
\hline Joseph Csáky & "Composition" & Frans Masereel & $\begin{array}{l}\text { "Femme a Montmartre"; } \\
\text { "Le Port de Boulogne"; } \\
\text { "Portrait de Le } \\
\text { Fauconnier" }\end{array}$ \\
\hline André Dérain & $?$ & André Masson & "La Ville Endormie" \\
\hline Germaine Derbecq & $\begin{array}{l}\text { "La Foire"; } \\
\text { "Nature Morte" }\end{array}$ & Joan Miró & $?$ \\
\hline Raoul Dufy & "Paysage" & $\begin{array}{l}\text { Joaquim do Rego } \\
\text { Monteiro }\end{array}$ & “Le Repos” (óleo) \\
\hline Eekman & $?$ & $\begin{array}{l}\text { Vicente do Rego } \\
\text { Monteiro }\end{array}$ & $\begin{array}{l}\text { "Le Tennis" (óleo); } \\
\text { "La Femme à la Biche" } \\
\text { (óleo); "Les Tullipes" } \\
\text { (guache) }\end{array}$ \\
\hline Farkas & "Tete de Femme" & Georges Papazoff & "Les Oiseaux" \\
\hline Fasini & “Composition” & Jules Pascin & (Quatro águas-fortes) \\
\hline Flouquet & "Crucifixion" & Pablo Picasso & "Arlequins" (guache) \\
\hline Fotinsky & $?$ & Valentine Prax & "Composition" \\
\hline $\begin{array}{l}\text { Tsuguharu } \\
\text { Léonard) Foujita }\end{array}$ & "Porte de Vanves" & Rendon & "Composition" (ou \\
\hline Genevieve Gallibert & "Bords de la Seine" & Roux & $?$ \\
\hline Albert Gleizes & "Composition" & Sandoz & $\begin{array}{l}\text { "Pochade"; } \\
\text { "Composition" (Qua- } \\
\text { tro pinturas no total) }\end{array}$ \\
\hline Gounaro & $\begin{array}{l}\text { "Pannier de Fruits"; } \\
\text { "Tete de Femme" }\end{array}$ & Sénabré & "Chien et Poisson" \\
\hline Juan Gris & $?$ & Gino Severini & $\begin{array}{l}\text { "Vierge à l'Enfant" } \\
\text { (guache) }\end{array}$ \\
\hline Marcel Gromaire & "Nu" & Sterling & $\begin{array}{l}\text { "Le Bateau Rouge"; } \\
\text { "Petite Fille" }\end{array}$ \\
\hline Alice Halicka & "Danseuses" & Léopold Survage & $\begin{array}{l}\text { "Port de Treboul"; } \\
\text { "Le Canigou" }\end{array}$ \\
\hline Auguste Herbin & $\begin{array}{l}\text { "Abstraktions" } \\
\text { (um óleo } \\
\text { e três aquarelas) }\end{array}$ & Kristians Tonny & $\begin{array}{l}\text { “Animaux” (Duas } \\
\text { águas-fortes) }\end{array}$ \\
\hline Max Jacob & ? & Georges Valmier & "Nature Morte" \\
\hline Laglenne & "Nature Morte" & Vines & "Nature Morte" \\
\hline La Serna & $\begin{array}{l}\text { "Tete de Marin"; } \\
\text { "Nature Morte" }\end{array}$ & Maurice Vlaminck & “Paysage” \\
\hline Lahner & $?$ & Eugéne Zak & "Femme à la Fleur" \\
\hline
\end{tabular}




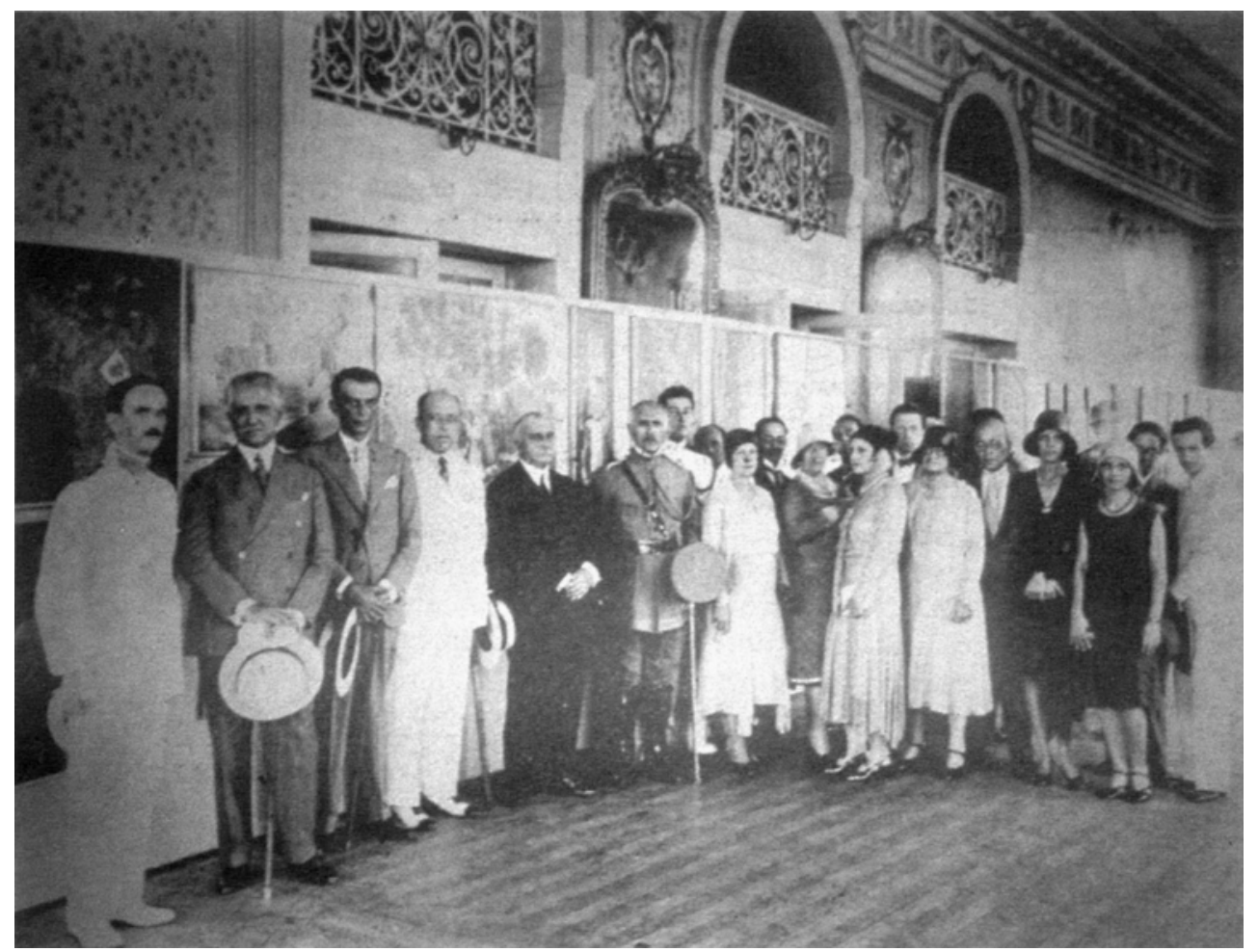

Detalhe da montagem da exposição no salão nobre do Teatro Santa Isabel (foto publicada na revista P'ra Você, 29 de março de 1930)

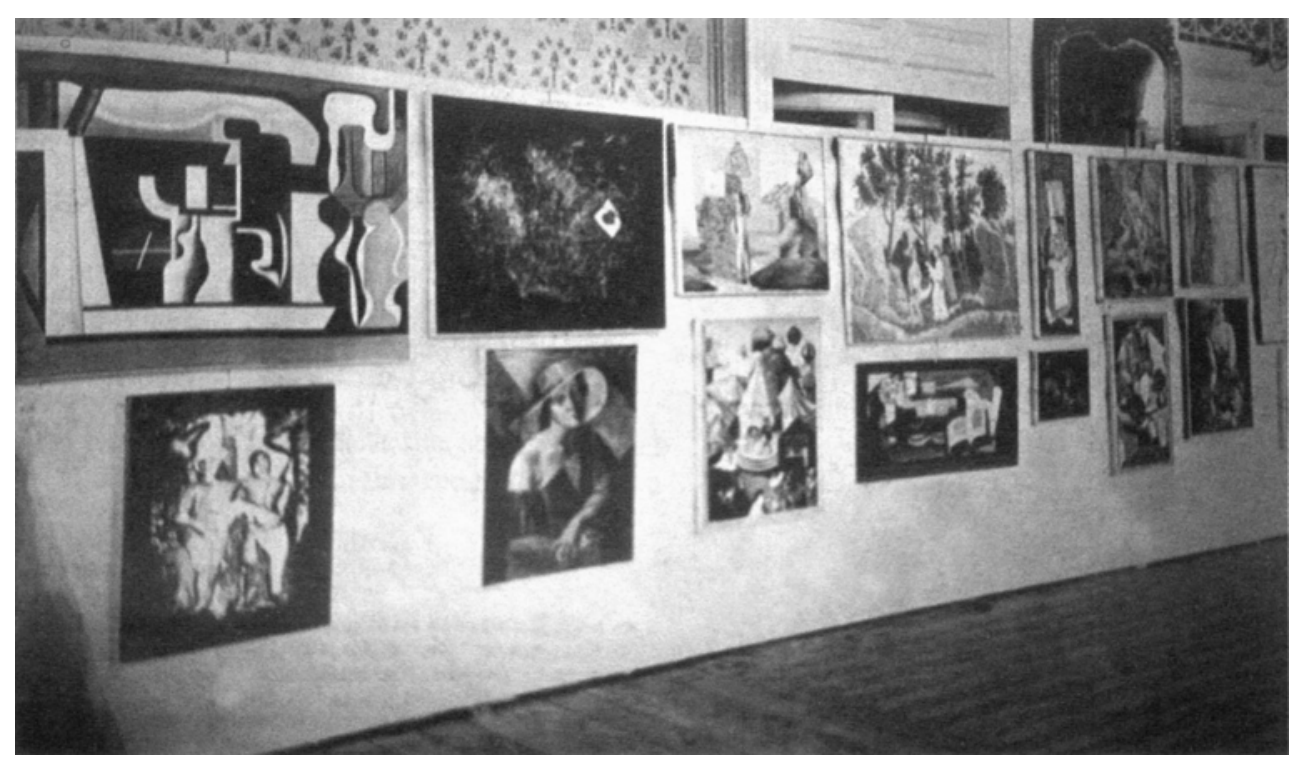

Vernissage da exposição da Escola de Paris no salão nobre do Teatro Santa Isabel (foto publicada na revista P'ra Você, 29 de março de 1930) 
Para que se tenha uma idéia mais precisa acerca do teor de novidade que a exposição da Escola de Paris trazia para o mundo das artes plásticas recifense e brasileiro de 1930, basta observar, no quadro na página anterior, a lista dos artistas e obras que compunham a mostra.

Esse quadro foi construído a partir das informações, nem sempre coincidentes, contidas em fontes diversas: jornais da época, Marconi (1970) e Zanini (1971, 1983, 1997). Como não parece ter sido produzido um catálogo para a expo sição no Recife (ao contrário do que aconteceu no Rio de Janeiro e em São Paulo), não é possível ter certeza quanto à inclusão ou exclusão de cada um dos trabalhos nele citados. É fora de dúvida, porém, que as obras mais importantes - incluindo as de Pablo Picasso e Vicente do Rego Monteiro - estiveram expostas no salão nobre do Teatro Santa Isabel, assim como é possível que outras não citadas tenham participado da exposição. Registre-se ainda que, na sua passagem por São Paulo, a mostra foi acrescida de telas pintadas por Tarsila do Amaral, com quem Vicente havia travado conhecimento em Paris no início da década de 1920.

Além de muitos dos nomes expostos serem já consagrados no cenário artístico mundial, a mostra foi significativa também por um outro e mais específico motivo: como observou Antonio Bento (1994:62), os trabalhos exibidos de Auguste Herbin (um óleo e três aquarelas) foram, "[s]em nenhuma dúvida", as primeiras abstrações trazidas ao Brasil. Considerando-se ser apenas após a Segunda Grande Guerra que artistas brasileiros começam a se dedicar, de modo sistemático, à pintura e à escultura não-representacional, a presença das obras de Herbin indica, por si só, o caráter pioneiro da mostra organizada e trazida ao país por Vicente do Rego Monteiro (10).

\section{'Recebendo' Picasso}

A notícia de que a exposição da Escola de Paris estava para chegar ao Recife despertou a curiosidade e o interesse dos pernambucanos. As expectativas criadas na cidade ecoaram em várias matérias de jornais sobre $\mathrm{o}$ evento, mencionado em A Província (19/3/1930:3) como "uma oportunidade magnífica para o público culto do Recife se pôr em contato com os grandes nomes da pintura moderna", inclusive Pablo Picasso, "o grande mestre do cubismo". Com a mesma convicção, Antônio Freyre (1930) anunciava a mostra como "uma missão a que os centros culturais do Brasil não se poder[iam] mostrar indiferentes". Ademais, transpirava dos jornais locais um orgulho pouco disfarçado do fato de ser um conterrâneo o responsável pela inédita vinda ao Brasil de uma grande exposição internacional de artes plásticas; era clara ainda a satisfação por Vicente do Rego Monteiro ter 
reservado ao Recife a primazia de inaugurar mostra tão importante e também pelo incontestável pertencimento do pintor pernam-bucano ao grupo de artistas que formava a Escola de Paris (Câmara, 1930).

Apesar do tom ligeiramente ufanista das notícias de jornal, é possível nelas discernir, nos dias que antecedem a abertura da exposição, um certo nervosismo e alguma apreensão sobre qual seria a reação dos recifenses diante das inovações estéticas contidas nos trabalhos expostos. De fato, o temor pela incompreensão das obras a serem exibidas levou o próprio jornal A Província (21/3/1930:3) a fazer um inusitado apelo aos seus leitores no dia mesmo da inauguração do evento: "Quaisquer que sejam as reações de ordem diversa que cada um possa sentir, é sob o ponto de vista de documentação que nos devemos colocar diante desta manifestação de arte".

P. Picasso: "Arlequins" (s.d.) (reprodução publicada em Renovação, nov. 1939)

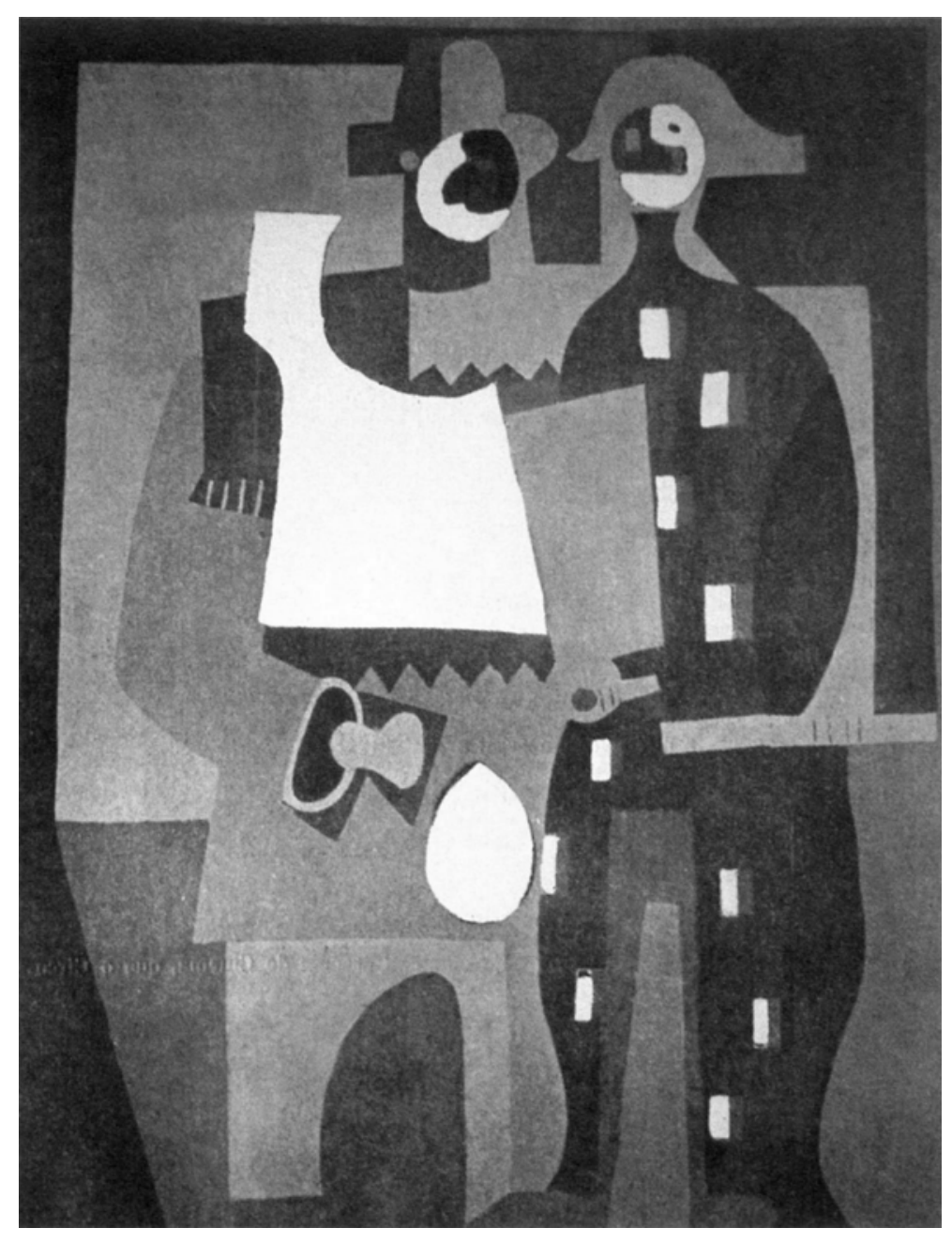


Uma matéria da revista P'ra Você (29/3/1930:12), por sua vez, parece querer lembrar que uma possível má acolhida aos artistas da Escola de Paris na cidade não deveria causar espanto. Afinal, diz o autor da nota, algumas das novidades estéticas presentes na mostra já haviam sido anunciadas e duramente criticadas no Recife quando da exposição, um ano antes, dos desenhos e aquarelas de Cícero Dias. Naquela ocasião, os “críticos" e "estetas" pernambucanos, irritados, teriam desqualificado os trabalhos de Dias como mero "blague" do artista.

Os receios externados pareciam ter fundamento. Além das notas informativas quanto à afluência das pessoas à exposição e à sua data de encerramento, as poucas matérias opinativas sobre a mostra davam notícia do grau de estranhamento do público pernambucano diante da face moderna da pintura européia. Nenhum testemunho é mais eloqüente a este respeito do que a crônica de Ascenso Ferreira publicada em A Província (30/3/ 1930 , seção 2:3). Segundo a viva descrição do poeta, todos que iam ao Santa Isabel contemplavam os quadros, mas, em sua maioria, "se mostra[va]m reservados em dar uma opinião definitiva" sobre o que viam. Fica claro, contudo, que "não gosta[va]m do que est[avam] a contemplar". Ainda de acordo com Ascenso (1930), sente-se nos olhos dos visitantes que nenhuma emoção grandiosa lhes vai n'alma, nenhum frêmito de entusiasmo lhes sacode os nervos impelindo-os a um grito de comoção: 'Danou-se', 'Está danado de bom!', 'Bonito como o cão!'.

Em artigo onde faz um balanço da mostra da Escola de Paris, um jornalista não identificado de A Provincia (3/4/1930:3) também admite que, embora tenha sido uma "oportunidade excelente" para se conhecer alguns do "mestres mais notáveis da arte moderna", "para uns a exposição constituiu um desapontamento". A despeito do tom conciliatório e contido do artigo, o autor se confessa decepcionado com aqueles que não souberam aproveitar tão rara oportunidade de contato com a produção artística européia, reafirmando a importância do evento: “A exposição que se encerra hoje em Pernambuco teve um aspecto cultural que nenhum homem inteligente e ao par do movimento artístico contemporâneo poderá, conscientemente, desdenhar".

Embora despretensiosa, é possível inferir, desta última afirmação, uma sugestão acerca das possíveis razões da má receptividade à mostra: se o reconhecimento do valor das obras expostas requeria que o público estivesse “ao par do movimento artístico contemporâneo", é possível supor que a rejeição observada tenha sido devida, principalmente, à pouca familiaridade dos recifenses com os estilos modernistas europeus. Caso esta hipótese seja verdadeira, o fracasso da exposição não pode ser visto, portanto, como “inex- 
plicável" ou como indicador de uma aversão dos pernambucanos à arte moderna per se, mas apenas, como ensina Pierre Bourdieu (1993a), resultado de uma divergência entre os códigos culturais a que os quadros faziam referência e aqueles de que os presentes ao Teatro Santa Isabel dispunham para apreciá-los. De fato, uma breve análise do conteúdo desses códigos revela que não eram poucas as diferenças ali presentes.

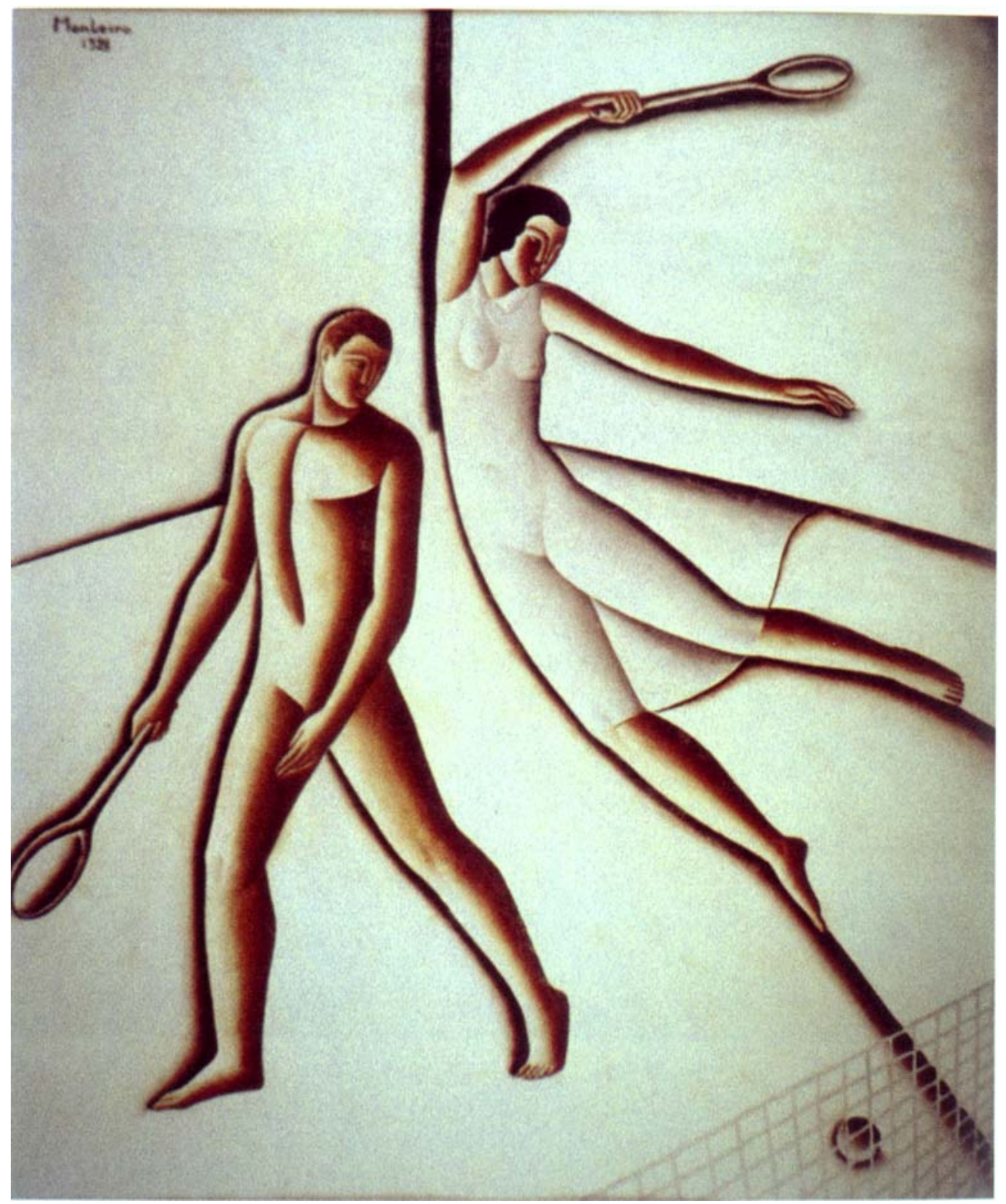

Vicente do Rego Monteiro: "Le Tennis” (1928)

(reprodução publicada no livro Vicente do Rego Monteiro: pintor e poeta) 
A codificação das telas expostas no Recife em março de 1930 remetia, de modo enfático, ao processo de autonomização do campo artístico francês, iniciado ainda nas últimas décadas do século XIX. Os significados maiores desse processo - que ganhou impulso a partir das inovações pictóricas de Edouard Manet - foram a ruptura com os valores acadêmicos e extraplásticos que predominavam no universo artístico francês e a fratura do poder detido pelas instituições que os sustentavam, como a Ecole des Beaux-Arts e as competições oficiais. Desde então, e principalmente nas três primeiras décadas do século XX, a cultura européia deixou de valorizar, nas artes plásticas, a capacidade de narração e de representação realista do mundo, tão privilegiada anteriormente; engajou-se, ao contrário, na valorização e legitimação dos aspectos intrínsecos à matéria plástica de que se constituem telas, desenhos e esculturas (11).

Esta reelaboração das convenções de apreciação de obras de arte não transformou, contudo, apenas os modos de ver tais objetos. Ao modificar os códigos culturais de valoração e percepção da expressão artística há muito vigentes, tal redefinição terminou também por reforçar a busca de novas maneiras de fazer arte (Anjos Jr., 1997). Não surpreende, portanto, constatar que uma das principais características da arte moderna tenha sido a sua continuada capacidade de refletir criticamente sobre as próprias formas e materiais que constituem o artefato artístico, enfatizando suas qualidades plásticas e abstratas (Greenberg, 1986). Movimentos como impressionismo, fovismo, cubismo, futurismo e expressionismo emergiram, ao longo das décadas que antecederam a exposição no Recife, como reflexões críticas sobre a natureza singular e autônoma do objeto de arte no mundo moderno, tendo sido os responsáveis pela sedimentação dos códigos estéticos próprios ao modernismo.

Os códigos culturais dominados pelo público recifense, por sua vez, remontavam exatamente ao tipo de arte que aqueles movimentos buscavam superar e suceder. Do que se apreende do exame de reproduções de pinturas feitas em Pernambuco antes de 1930 e também de relatos de artistas e historiadores (Cláudio, 1982), é razoável supor que, em sua larga maioria, aqueles que visitaram a exposição da Escola de Paris se aproximavam dos objetos artísticos munidos de uma capacidade de decodificação estética limitada pelos valores acadêmicos e pré-modernos que, ainda àquela época, eram exaltados no campo das artes plásticas recifense. Esta limitação é evidenciada não somente pela reação "negativa" do público diante dos quadros expostos, mas também por sua incapacidade de formular um discurso capaz de explicitar as razões para tal recepção. Impotentes diante de códigos que desconheciam, os críticos locais se mostravam, conforme aponta uma das poucas matérias positivas com relação à mostra, "seriamente encabulados" 
por não compreenderem como a cultura européia, "berço da civilização e do espiritualismo", poderia produzir e exaltar algo que, para eles, não passava de "maluquice" (P'ra Você, 29/3/1930:12).

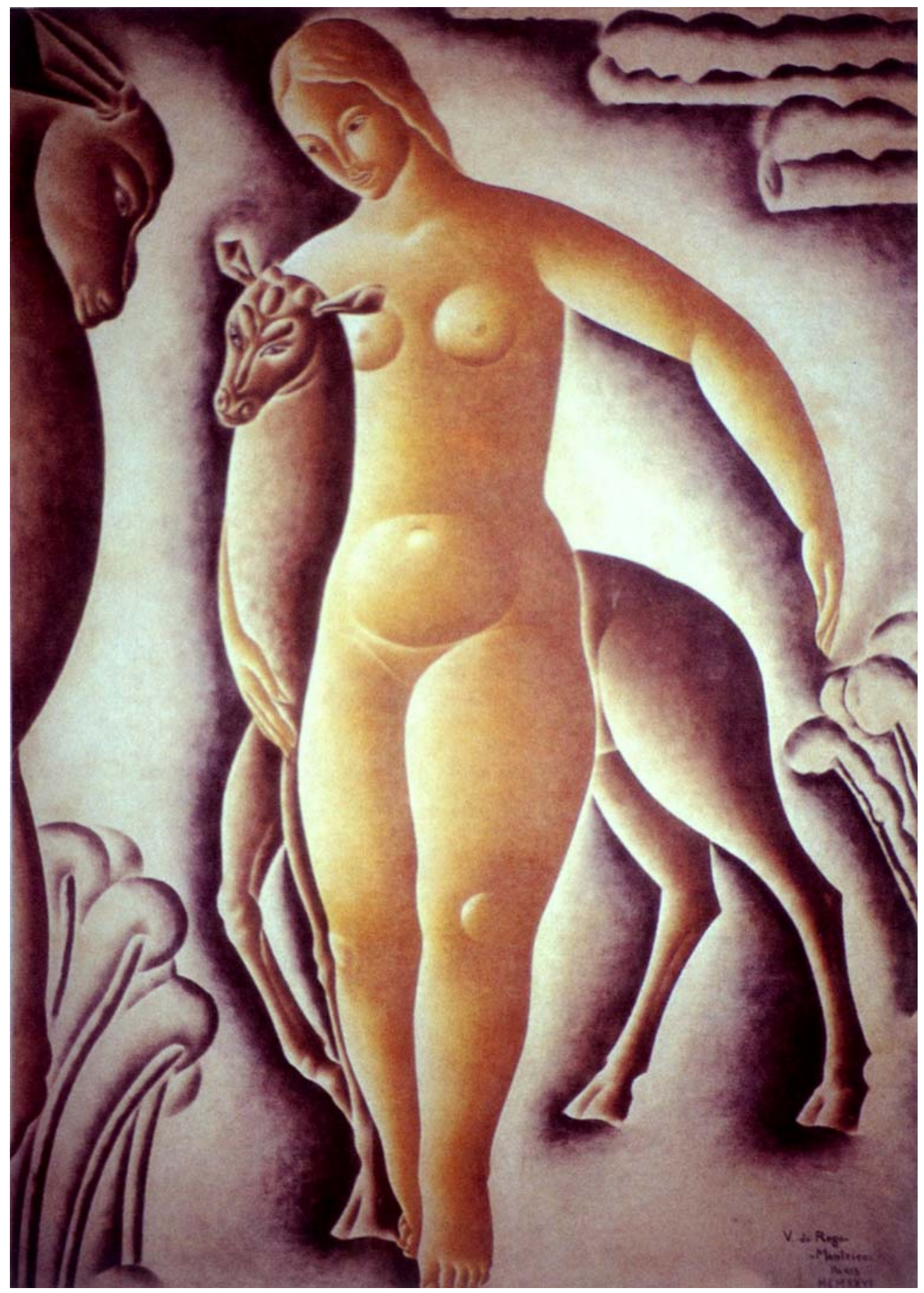

Vicente do Rego Monteiro: "Femme a la Biche" (1926)

(reprodução publicada no livro Vicente do Rego Monteiro: pintor e poeta) 
O tipo de concepção artística entendida - e, portanto, apreciada pelo público local é exemplificado nos (auto)retratos e paisagens produzidos por Henrique Elliot e Eugênio Lassaily, os quais, a despeito do uso de tons impressionistas, primavam pela fidelidade anatômica aos modelos oferecidos pela natureza. Tome-se como exemplo o auto-retrato pintado por Elliot em 1920. Alguém que o observa percebe, sem maiores esforços, que se trata de um senhor com ares burgueses, pouco passado dos 50 anos, que usa um chapéu comum à época e fuma seu charuto ou cigarro de palha. $\mathrm{O}$ único "desvio" de um retrato puramente acadêmico está no uso de pinceladas largas para marcar, na face do pintor, um ar melancólico ou mesmo entediado. Nada, porém, que causasse estranheza ou se indispusesse com os códigos estéticos então dominantes.

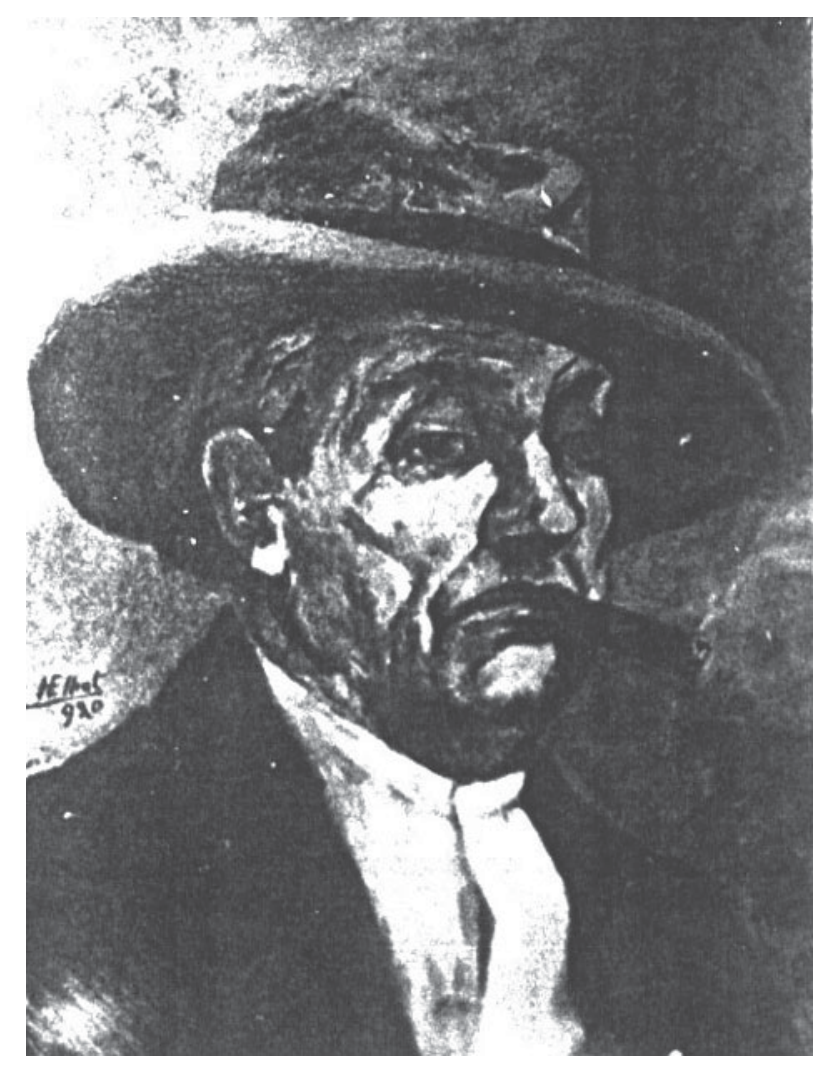

Henrique Elliot: “Auto-retrato” (1920) (reprodução publicada no livro Artistas de Pernambuco)

Deste modo, pode-se afirmar que a reação conservadora do público recifense com relação às propostas estéticas apresentadas na exposição de 1930 é explicada pela indisponibilidade - naquele momento da vida cultural da cidade - das 'lentes' necessárias à compreensão dos códigos nelas contidos, e não pelo "propósito de não entender", como um desanimado Géo-Charles 
chegou a pensar (Ferreira, 1930). Conforme afirma Bourdieu (1993a), a percepção imediata e adequada de uma obra somente pode acontecer se os códigos culturais que tornaram o artefato artístico possível forem completamente dominados pelo observador, de tal forma que este possa decifrar os significados daqueles. E embora seja certo que o público recifense - membros da alta sociedade, pelo que se depreende dos relatos contemporâneos - tivesse informações e "treinamento" adequados para apreciar a produção artística européia anterior a Manet, não possuía a “competência artística” necessária à decifração dos códigos das obras que compunham a exposição da Escola de Paris. O depoimento de Ascenso Ferreira (1930) sobre a recepção da mostra é esclarecedor acerca da origem deste desacordo entre códigos culturais:

Dir-se-á que os quadros expostos não têm valor?

Dir-se-á que são imbecis os visitantes do grande salão?

Nem uma coisa nem outra: - Questão apenas de um dogma aferrado nas consciências, espécie de tapume passado nos olhos de uma geração.

Aproveitando para destilar um pouco de seu desprezo pelos donos do poder em Pernambuco, Ascenso complementa mordazmente sua análise:

Os velhos papudos, com a idéia entulhada no lixo de uma falsa cultura clássica em que se afundaram, mercê do comércio barato de traduções - gente que se baba de entusiasmo vendo papai-Alberto de Oliveira descobrindo ninfas e tritões no planalto central de Goiás, gente para quem a beleza é a Vênus-Cotó de Milo ou os fardões agaloados da Academia de Letras do Brasil, essa gente não pode compreender nem sentir o gênio de Picasso [...]

Foi, portanto, o "tapume [dos códigos acadêmicos] passado nos olhos" dos recifenses que os impediu de pôr as 'lentes' adequadas à operação de decifração necessária à recepção das telas expostas no salão nobre do Teatro Santa Isabel. E dado o tamanho do descompasso existente entre os códigos dominados pelo público e aqueles incorporados às obras, pouco importa saber se havia ou não disposição dos recifenses para entender o significado das inovações artísticas apresentadas. Ainda que a houvesse, códigos culturais não podem ser instantaneamente trocados ou adquiridos. Eles mudam lentamente através de um processo cognitivo que envolve a ação pedagógica dos grupos sociais de que os indivíduos fazem parte e das instituições educacionais, políticas e artísticas com que interagem (DiMaggio, 1994).

Para que o público do Recife dominasse, já àquele momento, os códigos estéticos que permitiriam o entendimento das inovações trazidas pela Escola 
de Paris (ainda que para delas discordarem), seria preciso que instituições próprias ao campo das artes plásticas (museus, galerias, escolas de arte etc.) funcionassem ativa e autonomamente na cidade, livres de determinações valorativas externas e capazes de privilegiar a forma - e não a função - da obra de arte (Bourdieu, 1993c). O dinamismo dessas instituições seria fundamental para o estabelecimento de uma cadeia de cooperação entre os artistas locais, o mercado distribuidor e o público, por meio da qual novas informações e códigos estéticos seriam continuamente introduzidos, testados e gradualmente legitimados ou rejeitados por seus participantes, eventualmente diversificando o repertório estilístico ao qual os recifenses seriam capazes de responder (positiva ou negativamente).

Contudo, e apesar de os muitos artistas então trabalhando na cidade, tal arranjo cooperativo - o qual levou Howard Becker (1974) a sugerir que a arte seria uma "ação coletiva" - ainda não se havia consolidado no Recife dos anos 20. Os artistas, seguros da fidelidade de uma pequena clientela que fazia modestas exigências estéticas (a não ser a reprodução da natureza), não tinham por que arriscar o envolvimento com estilos de incerta receptibilidade. Quanto ao mercado de arte local, embora sejam poucas as informações disponíveis sobre seu funcio-namento nas três primeiras décadas do século XX, é razoável supor que fosse quase inexistente. Depoimentos de artistas ligados ao "Atelier Coletivo" - em atividade entre 1952 e 1957 - dão conta de que, mesmo na década de 1950, ainda não havia mercado de arte formal em Recife. Vendas, quando aconteciam, eram fruto de uma transação direta entre o artista e o apreciador de obras de arte, entre o produtor e o consumidor, quando não o resultado de encomenda do poder público (Cláudio, 1979) (12). Por fim, o público, privado de contato continuado com a produção modernista, não tinha meios de adquirir as informações necessárias à avaliação e julgamento das novas tendências artísticas.

Foi por ser pequeno e pouco dinâmico, portanto, que o campo das artes plásticas recifense não conseguiu um grau de autonomia suficiente para realizar a soldagem das relações entre artistas, mercado de arte e público, desta forma refreando as potenciais circulação e aprendizagem, por parte de todos os agentes nele envolvidos, de novos códigos culturais. Frente a essa fragilidade institucional, o mundo artístico recifense não pôde sequer se beneficiar do confronto entre regionalismo e modernismo experimentado pelos escritores locais nos anos 20, perdendo a oportunidade de assimilar algumas das questões conceituais ali discutidas. O quase desconhecimento de códigos estéticos que não os da arte acadêmica impediu, assim, que pintores e público pudessem acostumar o olhar a ver nas pinturas o que já liam nos poemas da época. Em ambiente tão acomodado, não espanta mesmo 
que um "Arlequim" pintado por Picasso, exibindo "músculos de aço desmembrados das bombas de pressão", tenha desagradado àqueles que foram 'receber' o pintor espanhol no Teatro Santa Isabel (Ferreira, 1930).

\section{Conclusão}

Perante o ineditismo da exposição da Escola de Paris e a importância dos artistas nela representados, parece mesmo difícil, em uma primeira aproximação, entender as razões pelas quais a mostra teria sido tão mal recebida à época de sua realização.

O espanto diante desta 'injustiça' histórica só diminui quando os códigos culturais que informavam o 'olhar' do público recifense são reconstituídos e comparados com aqueles que, no mesmo momento, animavam o campo artístico francês.

As enormes diferenças existentes entre tais códigos bloquearam a possibilidade de decifração do sentido e do valor das obras expostas, a despeito tanto da 'indiscutível' qualidade a elas já então atribuída pela historiografia da arte quanto dos "dois metros quadrados de cultura clássica e cinco arrobas de erudição" possuídos pelos que visitaram a exposição (Ferreira, 1930).

A emergência do 'olho' moderno do público local estava, portanto, ainda a depender da constituição de um campo artístico autônomo na cidade, capaz de cimentar o trabalho cooperativo entre artistas, mercado e público em torno de valores intrínsecos à matéria plástica. Na incontornável ausência desta autonomia, nada mais natural, então, que o recifense tenha se "fecha[do] em copas" (ibid.) ante uma 'incompreensível' arte moderna e se refugiado no esquecimento do dia em que Picasso 'visitou' o Recife.

Notas

1 Foi no Teatro Santa Isabel que, nas últimas décadas do século XIX, se travaram os célebres embates poéticos entre Tobias Barreto e Castro Alves e onde Carlos Gomes regeu suas mais famosas óperas; foi lá também que Joaquim Nabuco realizou suas conferências abolicionistas e onde, já no início do século XX, o público recifense pôde assistir à companhia da bailarina russa Anna Pavlowa (Contraponto, 1950).

2 Em 1940 chegou ao Rio de Janeiro a "Exposição de Arte Francesa”, um “survey do neoclassicismo de David às tendências inaugurais do século XX" (Zanini, 1983:573). Registre-se, porém, que sua vinda ao Brasil se deveu, em larga medida, 
à deflagração da Segunda Guerra Mundial, o que impediu o retorno das obras de Caracas - sua última destinação no roteiro original da mostra - a Paris (Bento, 1994).

3 A última vez que a exposição de 1930 foi mencionada pela imprensa pernambucana parece ter sido no já longínquo ano de 1970, quando o jornalista Celso Marconi (1970) escreveu um breve e puramente descritivo artigo lembrando os 40 anos do evento.

4 Para uma discussão sobre as reações à chegada dos símbolos da modernidade ao Recife, ver Rezende (1996).

5 A campanha modernista em Pernambuco está documentada em Inojosa (19681969).

6 De acordo com o crítico Frederico Morais (1979), o grau de introversão da pintura pernambucana só encontra paralelo, na América Latina, naquela feita na Colômbia.

7 Embora não possuindo o caráter inovador da arte de Cícero Dias e Vicente do Rego Monteiro, é preciso registrar a importância da obra de quatro outros artistas modernistas pernambucanos: Manoel Bandeira, Joaquim Cardozo, Fédora do Rego Monteiro e Joaquim do Rego Monteiro.

8 Morando no Rio de Janeiro desde 1920, Cícero Dias retorna a Pernambuco em 1928 - aos 21 anos - para suas primeiras exposições no estado (nas cidades de Escada e Recife) e, no ano seguinte, para outra mostra de seus trabalhos (novamente em Escada e Recife), desta vez acompanhado de Mário de Andrade (Dias, 1993). Estas exposições estão, juntamente com a do pintor futurista português Jorge Barradas, realizada em 1923, dentre as poucas mostras de arte moderna de que há registro no Recife dos anos 20. A uni-las, porém - além da filiação modernista -, apenas o fato de terem ambas sido cercadas pela indiferença, quando não hostilidade, do público local ( $P$ 'ra Você, 29/3/1930; Azevedo, 1996).

9 As datas da exposição no Rio de Janeiro e São Paulo foram, respectivamente, 15 a 25 de maio e 6 a 20 de junho de 1930.

10 Ao menos o óleo de Herbin e outro de Marcoussis parecem ter sido adquiridos pela prefeitura do Recife por ocasião da mostra. Apesar da importância histórica destas obras, elas foram, por anos, usadas para decorar salas de funcionários da prefeitura, os quais desconheciam sua autoria e procedência (Zanini, 1983). As telas fazem parte, hoje, do acervo permanente do Museu de Arte Moderna Aloísio Magalhães (Recife).

11 Para uma descrição e análise detalhadas do processo de autonomização do campo artístico na França, ver Bourdieu (1993b).

12 Conforme atesta o estudo de Durand (1989), mesmo as cidades de vida cultural 
mais dinâmica do país - São Paulo e Rio de Janeiro - somente começam a institucionalizar um campo de artes plásticas na década de 1930.

Referências bibliográficas

A PROVÍNCIA. Uma grande exposição de arte moderna no Recife, 19 mar. 1930, p.3.

p.3.

Uma grande exposição de arte moderna no Recife, 20 mar. 1930,

A Escola de Paris em Recife, 21 mar. 1930, p.3.

. Exposição de arte moderna, 22 mar. 1930, p.3.

. Grande exposição de arte moderna, 29 mar. 1930, p.3.

. Grande exposição de arte moderna, 30 mar. 1930, p.3.

Grande exposição de arte moderna, 3 abr. 1930, p.3.

ANJOS Jr., Moacir. Moeda e arte no mundo moderno. Recife, Fundação Joaquim Nabuco (Série Trabalhos Para Discussão, n. 58/97), 1997.

AZEVEDO, Neroaldo Pontes de. Modernismo e regionalismo: os anos $20 \mathrm{em}$ Pernambuco. João Pessoa, UFPB/Recife, UFPE, 1996.

AYALA, Walmir. Vicente do Rego Monteiro: cubismo e muralismo. In: Vicente do Rego Monteiro: pintor e poeta, $5^{\text {a }}$ ed., Rio de Janeiro, Cor Editores, 1994.

BECKER, Howard. Art as collective action. American Sociological Review, v. 39, n. 6, p. 767-776, 1974.

BENTO, Antonio. Apresentação em 1920 no Recife. In: Vicente do Rego Monteiro: pintor e poeta, $5^{\text {a }}$ ed. Rio de Janeiro, Cor Editores, 1994.

BOURDIEU, Pierre. Outline of a sociological theory of art perception. In: The field of cultural production. Cambridge, Polity Press, 1993a.

. Manet and the institutionalization of anomie. In: The field of cultural production. Cambridge, Polity Press, 1993b.

The historical genesis of the pure aesthetic. In: The field of cultural production. Cambridge, Polity Press, 1993c.

CARVALHO, Ronald de. Duas exposições de pintura. O Jornal, 3 jul. 1921, p.1.

CÂMARA, Balthazar da. Exposição de arte moderna. Jornal Pequeno, 29 mar. 1930, p.1.

CLÁUDIO, José. Memória do atelier coletivo (Recife 1952-1957). Recife, Artespaço; São Paulo, Renato Magalhães Gouveia - Escritório de Arte, 1979. 
CLÁUdIO, José. Artistas de Pernambuco. Recife, Governo do Estado, 1982.

CONTRAPONTO. Edição Especial. Centenário do Teatro Santa Isabel, ano V, n. $12,1950$.

DIAS, Cícero. Anos 20. Rio de Janeiro, Editora Index, 1993.

DiMAGGIO, Paul. Social stratification, life-style, and social cognition. In: D.B. Grusky (org.). Social stratification: class, race, and gender in sociological perspective. Boulder, Westview Press. 1994.

DIMAS, Antônio. Um manifesto guloso. Prefácio a Freyre, Gilberto, Manifesto regionalista. Recife, Editora Massangana, 1994.

DURAND, José Carlos. Arte, privilégio e distinção. São Paulo, Perspectiva/Edusp, 1989.

FERREIRA, Ascenso. O salão de arte moderna do Teatro Santa Isabel. A Provincia, 30 mar. 1930, seção 2, p.3.

FREYRE, Antonio. O pintor Vicente do Rego Monteiro. A Província, 11 fev. 1930.

FREYRE, Gilberto. A pintura no Nordeste. In: Gilberto Freyre et al., Livro do Nordeste (1925). Recife, Arquivo Público Estadual, 1979 [ed. fac-similar].

FREYRE, Gilberto et al. Livro do Nordeste (1925). Recife, Arquivo Público Estadual, 1979 [ed. fac-similar].

GREENBERG, Clement. Towards a newer laocoon. In: J. O'Brian (org.). Clement Greenberg. The collected essays and criticism, v. 1, Perceptions and judgments 19391944. Chicago, University of Chicago Press, 1986.

INOJOSA, Joaquim. O movimento modernista em Pernambuco, 3 v. Rio de Janeiro, Gráfica Tupy, 1968-1969.

MARCONI, Celso. Arte parisiense veio ao Recife há 40 anos. Jornal do Commercio, 24 maio 1970, caderno II, p.4.

MONTEIRO, Vicente do Rego. Depoimento do pintor e poeta Vicente do Rego Monteiro (1969). In: Vicente do Rego Monteiro: pintor e poeta, $5^{\mathrm{a}}$ ed. Rio de Janeiro, Cor Editores, 1994.

MORAIS, Frederico. Artes plásticas na América Latina: do transe ao transitório. Rio de Janeiro, Civilização Brasileira, 1979.

P'RA VOCÊ. Exposição de arte moderna. 29 mar. 1930, p. 12-13.

REZENDE, Antônio Paulo. O Recife na década de vinte: modernidade e identidade. CLIO - Série Histórica do Nordeste, n. 16, p. 17-28, 1996.

ZANINI, Walter. Vicente do Rego Monteiro. São Paulo, Museu de Arte Contemporânea de São Paulo, 1971. 
História geral da arte no Brasil. São Paulo, Instituto Walther Moreira Salles/Fundação Djalma Guimarães, 1983.

ZANINI, Walter. Vicente do Rego Monteiro. Artista e poeta. São Paulo, Empresa das Artes/Marigo Editora, 1997.

RESUMO - EM MARÇO de 1930 o pintor Vicente do Rego Monteiro trouxe para o Re-cife uma exposição de obras dos principais representantes da chamada Escola de Paris, entre os quais cabe destacar Picasso, Léger, Miró e Braque. O evento, apesar da qualidade intrínseca das obras, encontrou uma alta dose de incompreensão. Neste trabalho mostra-se, à luz da contribuição de Pierre Bourdieu, terem sido as diferenças entre os códigos culturais do público e aqueles a que as obras faziam referência que impediram a decifração do sentido e do valor da exposição.

ABSTRACT - IN MARCH 1930 the painter Vicente do Rego Monteiro brought to Recife an exhibition of works by the main artists of the so-called School of Paris, among them Picasso, Léger, Miró and Braque. The event, in spite of the intrinsic quality of the works, met with widespread incomprehension. In this article is demonstrated, by using Pierre Bourdieu's contribution, that the differences between the cultural codes held by the public and those referred to by the works prevented the attendance from deciphering both the meaning and the value of the exhibition.

Moacir dos Anjos Jr. e Jorge Ventura de Morais são, respectivamente, pesquisador do Instituto de Pesquisas Sociais da Fundação Joaquim Nabuco e professor do Programa de Pós-Graduação em Sociologia da Universidade Federal de Pernambuco. A ordem dos autores reflete simplesmente a ordem alfabética de seus sobrenomes, pois ambos contribuíram igualmente para a composição deste artigo. 